\title{
Identification of a common reference gene pair for qPCR in human mesenchymal stromal cells from different tissue sources treated with VEGF
}

\author{
Josefine Tratwal ${ }^{\dagger}$, Bjarke Follin ${ }^{\dagger}$, Annette Ekblond, Jens Kastrup and Mandana Haack-Sørensen ${ }^{*}$
}

\begin{abstract}
Background: Human mesenchymal stromal cells from the bone marrow (BMSCs) are widely used as experimental regenerative treatment of ischemic heart disease, and the first clinical trials using adipose-derived stromal cells (ASCs) are currently being conducted. Regenerative mechanisms of BMSCs and ASCs are manifold and in vitro pretreatment of the cells with growth factors has been applied to potentially enhance these properties. When characterizing the transcriptional activity of these cellular mechanisms in vitro it is important to consider the effect of the growth factor treatment on reference genes (RGs) for the normalization of qPCR data.
\end{abstract}

Results: BMSCs and ASCs were stimulated with vascular endothelial growth factor A-165 (VEGF) for one week, and compared with un-stimulated cells from the same donor. The stability of nine RGs through VEGF treatment as well as the donor variation was assessed using the GenEx software with the subprograms geNorm and Normfinder. The procedure of stepwise elimination was validated by poor performance of eliminated RGs in a normalization experiment using VWF as target gene. Normfinder found the TATA box binding protein (TBP) to be the most stable single RG for both BMSCs and ASCs. The optimal number of RGs for ASCs was two, and the lowest variance for vWF normalization was found using TBP and YWHAZ. For BMSCs, the optimal number of RGs was four, while the two-RG combination producing the most similar results was TBP and YWHAZ.

Conclusions: A common reference gene, TBP, was found to be the most stable standalone gene, while TBP and YWHAZ were found to be the best two-RG combination for QPCR analyses for both BMSCs and ASCs through the VEGF stimulation. The presented stepwise elimination procedure was validated, while we found the final normalization experiment to be essential.

Keywords: Adipose-derived stromal cell, ASC, ADSC, MIQE, qPCR, Reference gene, Mesenchymal stromal cell, MSC, Vascular endothelial growth factor, VEGF

\section{Background}

Human bone marrow derived stromal cells (BMSCs) and adipose-derived stromal cells (ASCs) have made a significant impact on the field of regenerative medicine. Within the field of cardiac regeneration, BMSCs have been used frequently in clinical trials while the first clinical trials with ASCs stimulated with vascular endothelial growth factor (VEGF) is currently being conducted by our group [1,2]. BMSCs are the most extensively

\footnotetext{
* Correspondence: Mandana.Haack-Soerensen@regionh.dk

'Equal contributors

Cardiology Stem Cell Centre, The Heart Centre, Rigshospitalet, Copenhagen University Hospital, Juliane Maries Vej 20, dept. 9302, 2100 Copenhagen, University
Denmark
}

\section{Biomed Central}

(c) 2014 Tratwal et al.; licensee BioMed Central Ltd. This is an Open Access article distributed under the terms of the Creative Commons Attribution License (http://creativecommons.org/licenses/by/2.0), which permits unrestricted use, distribution, and reproduction in any medium, provided the original work is properly credited. The Creative Commons Public Domain Dedication waiver (http://creativecommons.org/publicdomain/zero/1.0/) applies to the data made available in this article unless otherwise stated. investigated cell type, however adipose tissue has received increasing interest as a source of stem cells due to easier harvest, a larger yield of stem cells and the fact that ASCs possess higher proliferative capacity compared to BMSCs [3]. The rationale behind the potential benefit of using the two cell types has primarily been suggested on the basis of their immunoregulatory properties, paracrine profiles, and capability to differentiate into various cell types [4-9]. When investigating these properties and how to enhance them in vitro, the first change within the cells is found at the transcriptional level. This change is detectable by quantitative real time polymerase chain reaction (qPCR) analyses, which is the preferred method for detecting changes in gene expression [10]. However, the 
qPCR method is sensitive to several errors in the experimental setup that may affect results. These errors could occur at different stages throughout the experiment and encompass variations in the amount of starting material, nuclear extraction, RNA integrity, cDNA loading, reverse transcription, and qPCR efficiency [11]. Thus, in order to compare qPCR results from different runs, or samples obtained from different tissues at various time points, a normalization step is necessary [12].

The most widely used method for normalizing qPCR data is comparison to values from reference genes (RGs) analyzed simultaneously on the same material [13]. The abundance of the normalization candidate gene must be closely related to the total amount of mRNA in the sample, in order to be able to correct for experimental errors [14]. In addition, it must exhibit stable expression during experimental conditions to be useful for normalization. Often an invariant endogenous gene is used as a RG with a constant expression level across all samples and experimental treatments. If the RGs are not stable through the treatment it could obscure actual changes and produce artifacts that contribute to misleading results and incorrect conclusions, thereby leading to unreliable publications [13]. The attention regarding selection of suitable RGs has increased in the past decade, from the geometric mean normalization proposed by Vandesompele et al., to experiment-specific RG investigations, and ultimately the "Minimum Information for Publication of Quantitative Real-Time PCR Experiments" (MIQE) guidelines [14,15]. The guidelines function as a universal checklist that investigators can follow, to produce the most reliable data when using qPCR [10].

In the field of cardiac regeneration, it has been proposed that endothelium-committed cells greatly enhance cell therapy outcome [16]. Ongoing clinical trials performed by our group serve to differentiate ASCs and BMSCs toward endothelial lineage for enhancement of angiogenic potential by stimulation with vascular endothelial growth factor (VEGF) $[2,17,18]$. This proangiogenic growth factor is known to promote endothelial cell proliferation, migration, and vessel permeability, and to differentiate BMSCs toward endothelial lineage $[19,20]$. The impact of VEGF treatment on ASCs and BMSCs is tested in vitro by the use of qPCR, where it is very important for both cell types to have established RGs that are stable through the VEGF treatment. A suitable RG in ASCs is not necessarily stable in BMSCs, therefore, it is important to validate whether the chosen RGs can be used in both cell sources under specific experimental conditions. No studies comparing choice of RGs between ASCs and BMSCs have been conducted previously to the authors' knowledge, which makes this study particularly interesting with regard to the ongoing debate of differences and similarities between these two cell types. Through this study we provide a simple stepwise selection procedure for choosing the RGs with focus on the impact on the final outcome. For the purpose we use specially designed software GenEx, more specifically the algorithms Normfinder and geNorm [14,21].

\section{Results}

To be able to apply the qPCR on VEGF pre-conditioned human mesenchymal stromal cells from the bone marrow and adipose tissue, a panel of RGs (Table 1) from relevant literature was chosen to find the correct RG for normalization. After confirming RNA purity, RNA integrity, primer efficiency, and products (Figure 1), a stepwise elimination of candidate RGs was performed in order to select the best-suited RG(s) from a list of acceptable ones.

\section{RNA and primer quality}

RNA purity was validated by excluding protein contamination with absorbance ratios of 1.8-2.2 at $260 \mathrm{~nm} / 280 \mathrm{~nm}$. RNA integrity was confirmed by RIN values of 10 for all donors (Additional file 1: Table S1). Primers (Table 1) for the qPCR were validated by dissociation curves (Additional file 1: Figure S1) and by efficiencies $\left(E=\left(10^{\frac{-1}{\text { Slope }}}-1\right) \cdot 100\right)$ of $100 \% \pm 10 \%$ with a correlation coefficient $R^{2}$ between 0.985 and 1.0 (Additional file 1: Table S2).

\section{RG candidate selection}

\section{Step 1: RG candidate expression levels}

The RG candidate $\mathrm{Cq}$ values were generally between 15 and 25 cycles, with no great difference between the VEGF treatment group and the control group for either ASCs or BMSCs (Figure 2). The selected RGs should preferably be expressed in amounts close to those of the target genes. The raw data for the outliers provided us with $\mathrm{Cq}$ values that were substantially lower than that of the gene of interest, as depicted in Figure 2 presenting median $\mathrm{Cq}$ values. Reference genes with a substantially greater difference in abundance compared to the gene of interest are not suitable. It would be incorrect to perform an analysis on putative reference genes that are unsuitable to be considered. Here our cutoff $\mathrm{Cq}$ value difference is 10 cycles. In order not to reduce the initial panel of reference genes completely, we didn't exclude more than the three genes mentioned at this stage.

We have investigated the impact of VEGF treatment in terms of initiation of endothelial differentiation in ASCs and BMSCs, after which endothelial target genes such as $\nu W F$ are expressed in relatively low amounts, and therefore detected around 30 cycles. Since EF1- $\alpha$, $A C T B$, and $18 S$ rRNA were the most abundant RGs in both ASCs and BMSCs, with Cq values far from our target, they were removed from the panel (Figure 2). This 
Table 1 Reference genes for qPCR

\begin{tabular}{|c|c|c|c|c|}
\hline Gene & Gene & $\begin{array}{l}\text { NCBI reference } \\
\text { sequence }\end{array}$ & Forward sequence & Cellular function \\
\hline \multirow[t]{2}{*}{ 18SrRNA } & \multirow[t]{2}{*}{$18 \mathrm{~S}$ ribosomal RNA } & \multirow[t]{2}{*}{ NR_003286.2 } & $\mathrm{F}=5^{\prime}-\mathrm{GTAACCCGTTGAACCCCATT-3^{ \prime }}$ & \multirow{2}{*}{$\begin{array}{l}\text { Small subunit of cytoplasmic } \\
\text { ribosomes }\end{array}$} \\
\hline & & & $\mathrm{R}=5^{\prime}-\mathrm{CCATCCAATCGGTAGTAGCG-3^{ \prime }}$ & \\
\hline \multirow[t]{2}{*}{ ACTB } & \multirow[t]{2}{*}{ beta-actin } & \multirow[t]{2}{*}{ NM_001101.3 } & 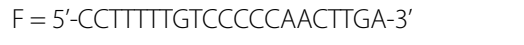 & \multirow{2}{*}{$\begin{array}{l}\text { Cytoskeleton structural protein; } \\
\text { motility, cytokinesis }\end{array}$} \\
\hline & & & 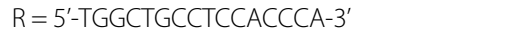 & \\
\hline \multirow[t]{2}{*}{ EFla } & \multirow[t]{2}{*}{ elongation factor-1 alpha } & \multirow[t]{2}{*}{ NM_001402.5 } & $\mathrm{F}=5^{\prime}-\mathrm{AGGTGATTATCCTGAACCATCC-3^{ \prime }}$ & \multirow[t]{2}{*}{ Translation } \\
\hline & & & $\mathrm{R}=5^{\prime}-\mathrm{AAAGGTGGATAGTCTGAGAAGC-3^{ \prime }}$ & \\
\hline \multirow[t]{2}{*}{ GAPDH } & \multirow{2}{*}{$\begin{array}{l}\text { glyceraldehyde 3-phosphate } \\
\text { dehydrogenase }\end{array}$} & \multirow[t]{2}{*}{ NM_002046.4 } & $\mathrm{F}=5^{\prime}-\mathrm{CAACGGATTTGGTCGTATTGG-3^{ \prime }}$ & \multirow{2}{*}{$\begin{array}{l}\text { Oxido-reductase in glycolysis anc } \\
\text { gluconeogenesis, transcription } \\
\text { activation, apoptosis }\end{array}$} \\
\hline & & & $\mathrm{R}=5^{\prime}-\mathrm{GCAACAATATCCACTTTACCAGAGTTAA-3^{ \prime }}$ & \\
\hline \multirow[t]{2}{*}{ GUSB } & \multirow[t]{2}{*}{ beta-glucuronidase } & \multirow[t]{2}{*}{ NM_000181.3 } & $\mathrm{F}=5^{\prime}-\mathrm{CTCATTTGGAATTTGCCGATT-3^{ \prime }}$ & \multirow{2}{*}{$\begin{array}{l}\text { Catalyzing hydrolysis of } \\
\text { B-D-glucuronic acid }\end{array}$} \\
\hline & & & 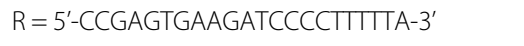 & \\
\hline \multirow[t]{2}{*}{ PPIA } & \multirow[t]{2}{*}{ peptidyl prolyl isomerase A } & \multirow[t]{2}{*}{ NM_021130.3 } & $\mathrm{F}=5^{\prime}-\mathrm{TCCTGGCATCTTGTCCATG-3^{ \prime }}$ & \multirow[t]{2}{*}{ Protein folding } \\
\hline & & & $\mathrm{R}=5^{\prime}$-CCATCCAACCACTCAGTCTTG-3' & \\
\hline \multirow[t]{2}{*}{ RPL13 } & \multirow[t]{2}{*}{ ribosomal protein L13a } & \multirow[t]{2}{*}{ NM_012423.3 } & $\mathrm{F}=5^{\prime}-\mathrm{CATAGGAAGCTGGGAGCAAG-3^{ \prime }}$ & \multirow{2}{*}{$\begin{array}{l}\text { Structural component of } 605 \\
\text { ribosomal subunit }\end{array}$} \\
\hline & & & $\mathrm{R}=5^{\prime}-\mathrm{GCCCTCCAATCAGTCTTCTG-3^{ \prime }}$ & \\
\hline \multirow[t]{2}{*}{ TBP } & \multirow[t]{2}{*}{ TATA-binding protein } & \multirow[t]{2}{*}{ NM_003194.4 } & 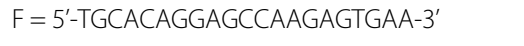 & \multirow{2}{*}{$\begin{array}{l}\text { RNA polymerase II transcription } \\
\text { factor }\end{array}$} \\
\hline & & & $\mathrm{R}=5^{\prime}-$ CACATCACAGCTCCCCACCA-3' & \\
\hline \multirow[t]{2}{*}{ YWHAZ } & \multirow{2}{*}{$\begin{array}{l}\text { tyrosine } 3 \text {-monooxygenase/ } \\
\text { tryptophan 5-monooxygenase } \\
\text { activation protein, zeta } \\
\text { polypeptide }\end{array}$} & \multirow[t]{2}{*}{ NM_001135702.1 } & $\mathrm{F}=5^{\prime}$-ACTTITGGTACATTGTGGCTTCAA-3' & \multirow[t]{2}{*}{ Signal transduction } \\
\hline & & & $\mathrm{R}=5^{\prime}-\mathrm{CCGCCAGGACAAACCAGTAT-3^{ \prime }}$ & \\
\hline
\end{tabular}

Information for the panel of selected reference genes with full name, NCBI reference sequence, forward and reverse primer sequences, and short description of cellular function.

initial exclusion resulted in the six RGs expressed in closest abundance to the target gene remaining for further analyses.

Step 2: Initial standard deviation-values from Normfinder Normfinder selects the most suitable RG based on the standard deviations (SDs) for intragroup donor variation and intergroup treatment variation. This analysis was performed taking the group classification of treatment into account, in order to verify that the candidate RGs were stably expressed and not regulated by treatment. The RG candidates with a large bias, an intergroup SD reaching or exceeding 0.2 were excluded (Table 2), leaving TBP, PPIA, YWHAZ, and GUSB for ASCs and TBP, $P P I A, Y W H A Z$, GUSB, and GAPDH for BMSCs for the final analysis.

\section{Step 3: Final output from geNorm and Normfinder}

Due to the selection in step 2, the software should not regard the effect of treatment in the next step of the

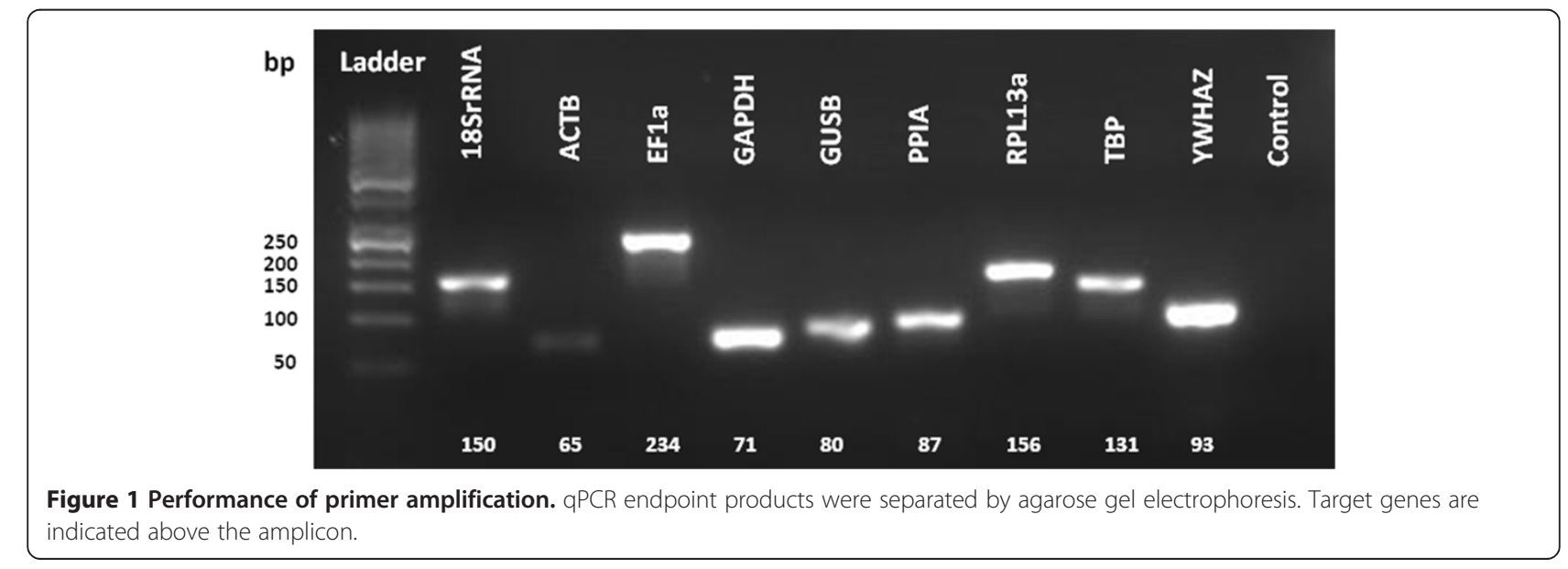




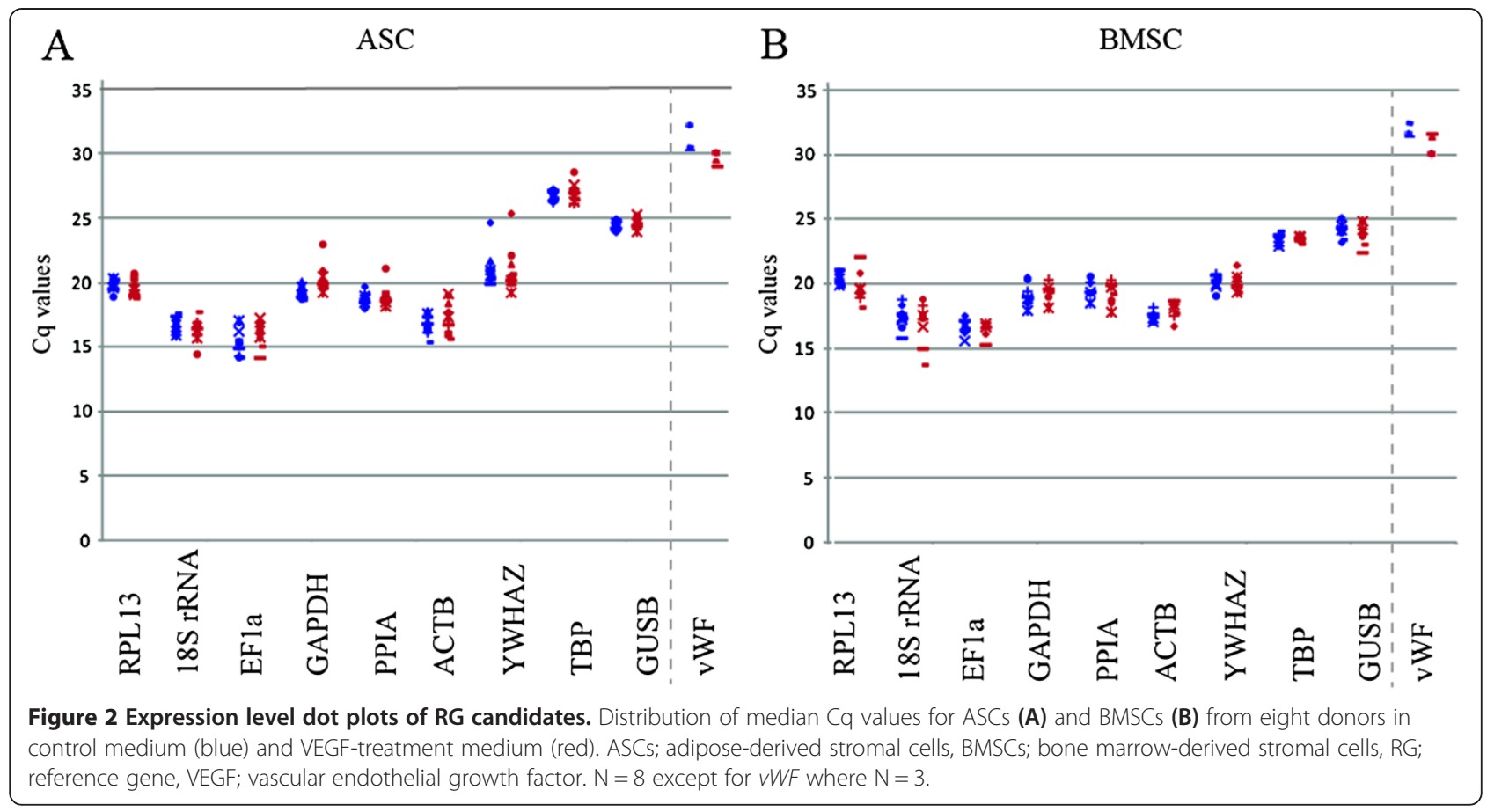

selection. This means that the final GenEx comparisons encompass both intragroup donor variation and intergroup treatment variation. According to Normfinder ranking order, TBP was found to be the most stable RG candidate through the VEGF treatment for both ASCs and BMSCs (Figure 3A and 3B). The optimal number of RGs was two for ASCs and four for BMSCs based on the accumulated SDs, which were reduced slightly by 0.009 and 0.003 respectively when compared to the use of a single RG (Figure 3C and 3D). In order to determine which RGs to use in combination we utilize intergroup treatment variation data calculated by Normfinder using only the remaining genes from Step 3 (Figure 3E). The

Table 2 Step two of elimination, showing ASC and BMSC reference gene intergroup variations

\begin{tabular}{lll}
\hline Gene name & ASC (SD) & BMSC (SD) \\
\hline GAPDH & $\pm 0.3855^{*}$ & $\pm 0.0780^{*}$ \\
GUSB & $\pm 0.0048^{*}$ & $\pm 0.0832^{*}$ \\
PPIA & $\pm 0.0977^{*}$ & $\pm 0.1028^{*}$ \\
RPL13 & $\pm 0.2843^{*}$ & $\pm 0.2865^{*}$ \\
TBP & $\pm 0.0090^{*}$ & $\pm 0.0016^{*}$ \\
YWHAZ & $\pm 0.1832^{*}$ & $\pm 0.0435^{*}$
\end{tabular}

Difference in mean expression of each gene between treated and untreated groups is shown as standard deviations (SD) in unit cycles. Genes were excluded at a cutoff value above 0.2 . Those with a SD below the threshold value (*) were included considered for further processing. 18S rRNA: $18 \mathrm{~S}$ ribosomal RNA, ACTB: beta-actin, EF1-a: Elongation factor 1-alpha, GAPDH: gluco phosphate dehydrogenase, GUSB: Beta-glucuronidase, PPIA: Peptidylprolyl isomerase A, RPL13a: Ribosomal protein L13-alpha, TBP: TATA box binding protein, YWHAZ: Tyrosine 3/tryptophan 5-monooxygenase activation protein. Genes not indicated with a star $(*)$ were deactivated in GenEx. sum of the different possible combinations were calculated and compared. The chosen combinations of TBP and YWHAZ for ASCs and TBP, GAPDH, PPIA and GUSB for BMSCs yielded a RG variation sum closest to zero.

GeNorm uses pair-wise comparison and sequential elimination to select the pair of RGs with highest correlation, indicated by the average expression stability $(M)$. $T B P$ and GUSB were found to be the best correlated RGs for ASCs and PPIA and GAPDH for BMSCs (Figure 4A and $4 \mathrm{~B}$ ) with a cut-off level at 0.5 .

\section{RG verification}

We compared the effect of normalization to various RG choices on the expression of a gene of interest (GOI), $v W F$, to validate our procedure of stepwise elimination of RG candidates and to attain a final selection of the most suitable RGs for future VEGF stimulation experiments. $v W F$ was chosen as positive control since it has been shown to be upregulated in other experiments by the same treatment, namely serum-deprivation combined with VEGF stimulation [19,22]. $v W F$ was normalized to RGs from each selection step of our procedure. For both ASCs and BMSCs, EF1- $\alpha$ was chosen from step 1 while RPL13 was chosen from step 2. From step 3, the single best RG found and the optimal number of RGs found by Normfinder and the two best correlated RGs given by geNorm were evaluated. Geometric mean of RG combinations were used, as suggested by Vandesompele et al. [14]. For ASCs, $v W F$ was normalized to TBP, the geometric mean of TBP and YWHAZ (Normfinder), or the geometric 

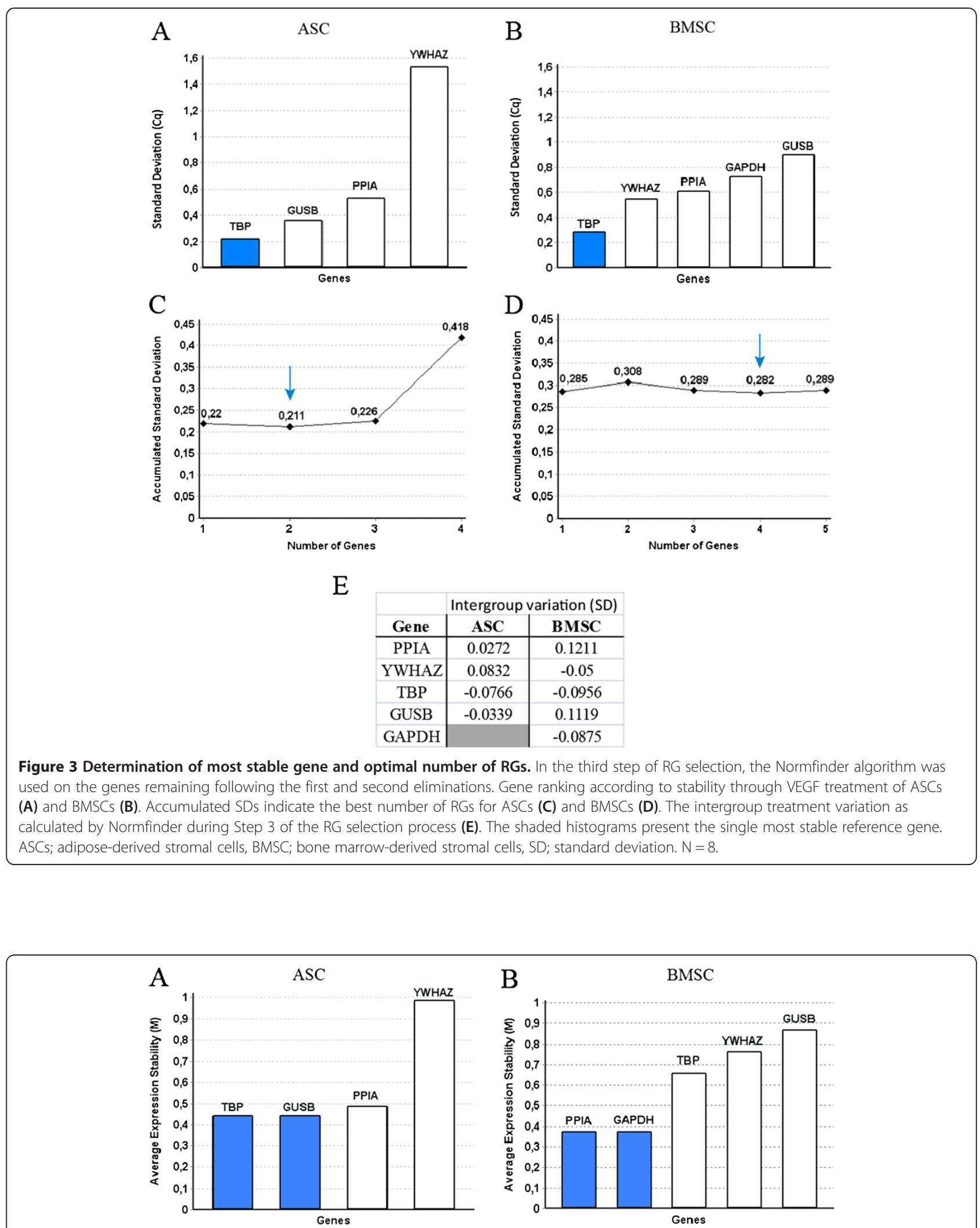

Figure 4 Determination of the best correlated genes. Average expression stability measure (M) calculated by pairwise comparison of RGs with sequential elimination of least stable RG by geNorm for ASCs (A) and BMSCs (B). The shaded histograms indicate the two most correlated genes. ASCs; adipose-derived stromal cells, BMSC; bone marrow-derived stromal cells, SD; standard deviation. $N=8$. 
mean of TBP and GUSB (geNorm) (Figure 5). For BMSCs, the normalization was also performed to $T B P$ alone, to the geometric mean of TBP, PPIA, GAPDH, and GUSB (Normfinder), to the geometric mean of PPIA and GAPDH (geNorm) (Figure 6A). Additionally, $v W F$ was normalized to the geometric mean of TBP and YWHAZ on the basis of Figure 6B.

\section{Poor results with normalization to eliminated RGs}

For both ASCs and BMSCs, EF1- $\alpha$ was chosen from step 1 while RPL13 was chosen from step 2 and the single best RG found by Normfinder, TBP, was chosen from step 3. When comparing the fold difference in $v W F$ expression for ASCs, no significant increase was observed for VEGF-treated ASCs compared to controls, regardless of the RGs used for normalization. The trend in a slight upregulation of $v W F$ was not investigated in depth, since this was not the aim of the study. For assessing our elimination procedure, comparison of the use of single RGs gave different results for the previously eliminated RGs compared to TBP. The variance in RPL13 results was markedly larger than the variance in $T B P$ results, while $E F 1-\alpha$ results showed a tendency of down-regulation of $\nu W F$, in contrast to results from all other normalizations. For BMSC, normalizing to any of the RG combinations or TBP alone included in step 3 of selection, proved $v W F$ to be significantly increased by the VEGF treatment. The results are not significant when normalizing to EF1 $\alpha$ or RPL13, and their variance was greater than that for $T B P$.

\section{Evaluating combinations of RGs}

Comparing the results from step 3 normalizations for ASCs, TBP alone produced results almost identical to either of the two combinations. Variance was lowest in TBP and highest in the geNorm combination, yet still almost identical (Figure 5).

For BMSCs, the fold expression increase obtained using TBP normalization was slightly below that for the Normfinder combination of RGs, while the geNorm combination resulted in a higher fold expression level (Figure 6A). Since the geNorm combination is the two best correlated RGs and the Normfinder combination was the best calculated number of RGs, we trust the expression level found using the Normfinder combination to be the most precise.

We further investigated whether a combination of two RGs could replace the four RG combination suggested by Normfinder for practical purposes. We found the geometric mean of TBP and YWHAZ to be the combination with the closest related and nearly identical $v W F$ fold change level, also with the lowest SEM across samples (Figure 6B). This combination was compared to the others in Figure 6A. When comparing the results of $\nu W F$ expression between the different RG combinations, only TBP is significantly different from

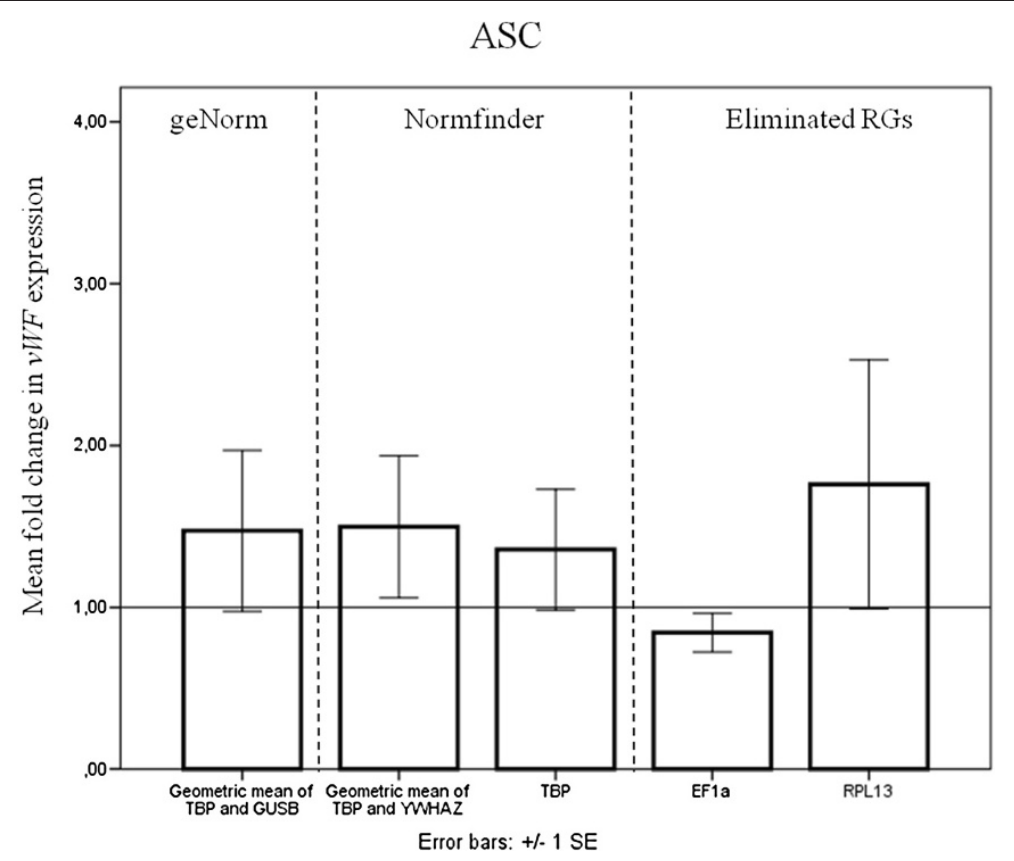

Figure 5 Difference in vWF expression normalized to different RGs. Normalization of VWF to various RGs for ASCs. The RGs were chosen from geNorm and Normfinder results. Two previously eliminated RGs, EF1- $a$ and RPL13 are included. ASCs; adipose-derived stromal cells, RG; reference gene, vWF: von Willebrand Factor. $\mathrm{N}=3$ and error bars represent SEM. 


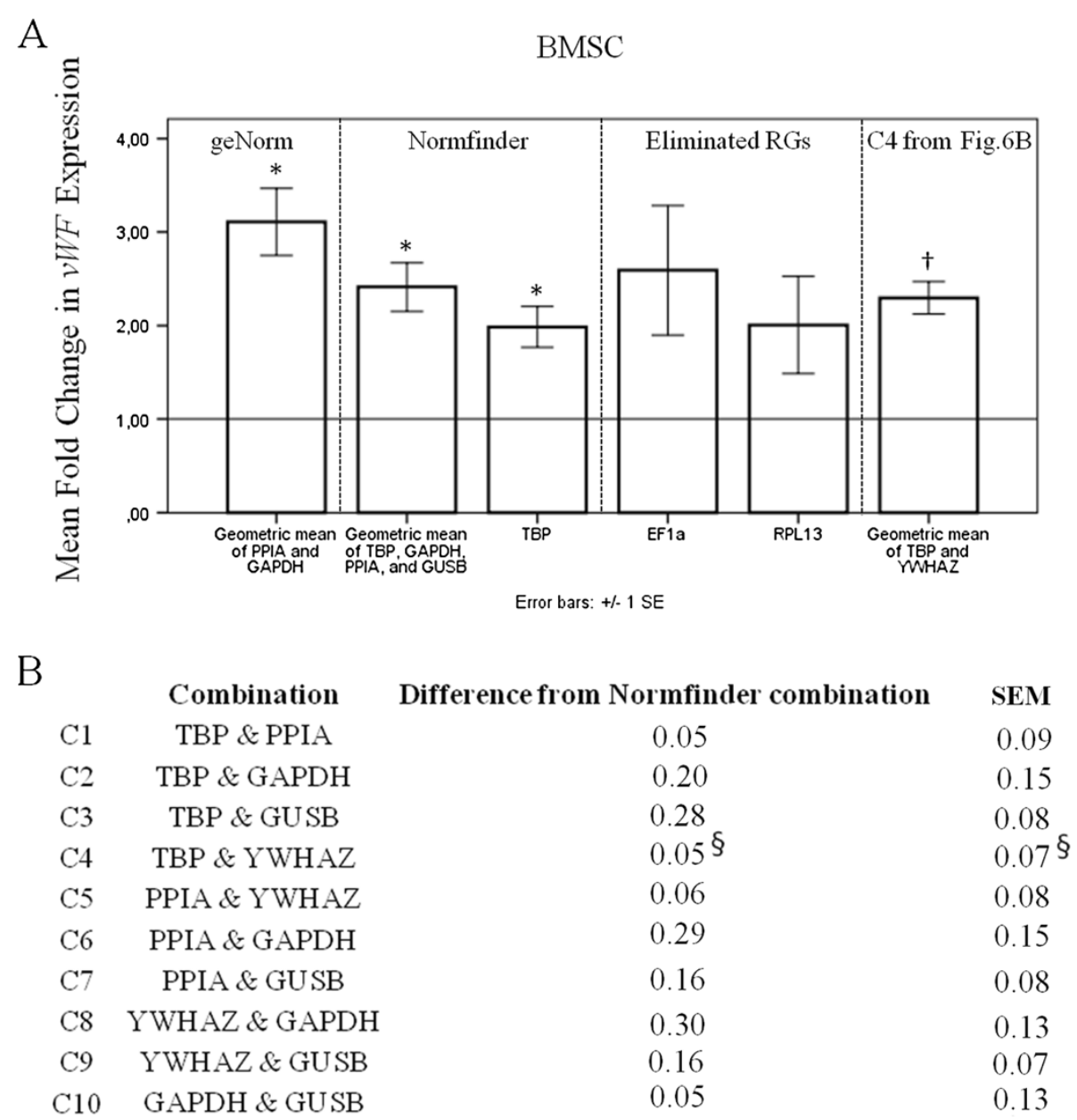

Figure 6 Comparison of BMSC vWF expression results from two-RG-combinations. Normalization of vWF to various RGs for BMSCs (A). The RGs were chosen by the same method as those in Figure $5 .{ }^{*}$ denotes significant $(p<0.05)$ VWF change, and + denotes significant correlation with results using the Normfinder combination of four-RGs. Test of two-RG combinations relative to results from the Normfinder combination of four genes (B). $2^{-\Delta \Delta C a}$ data were calculated for each RG combination using the geometric mean of the selected RGs, and compared to the mean of the results using Normfinder in the RG verification step. ${ }^{\S}$ denotes the combination producing results most closely related to those obtained using the Normfinder four-RG combination, and the combination producing the lowest standard deviation. BMSCs; bone marrow-derived stromal cells, VWF; von Willebran Factor, RG; Reference Gene, C; Combination. N $=3$ and error bars represent SEM.

the Normfinder combinations. However, only the results using the combination of TBP and YWHAZ, found from $\mathrm{C} 4$ in Figure $6 \mathrm{~B}$, were significantly correlated with the Normfinder combination.

\section{Discussion}

We compared different RGs for qPCR to detect the most optimal RGs for human ASCs and BMSCs, as these cell types are currently used in clinical trials, where they are stimulated with VEGF before injection into the myocardium of patients with chronic ischemic heart disease. When investigating the effect of the growth factor on the cells on transcriptional level, it is necessary to perform RG optimization for the production of properly normalized, reliable, and reproducible results.
The best single RG for both cell types in our experimental setup was $T B P$, which has been found to be stable through several other interventions using different stem cell lines or cancer cells $[15,23,24]$. TBP and $Y W H A Z$ were found to be the best two-RG combination for qPCR analyses of VEGF stimulation with serum deprivation in both ASCs and BMSCs.

Only four RGs were included in the final analysis for ASCs. It is noteworthy that the reduced panel from which an RG or combination of RGs was to be selected, were the exact same RGs that Fink et al. have shown to have stable expression in ASCs treated with hypoxia [15]. The other candidate RGs were excluded on the basis of having intergroup variation above the 0.2 cycle cutoff or because their expression level was significantly 
higher in comparison to potential genes of interest. This excluded RPL13 which was found by several groups to be the most stable RG in mesenchymal stem cells through different treatments $[25,26]$.

Though Normfinder found the optimal number of RGs to be two (Figure 3C), and geNorm found GUSB to be the RG best correlated with TBP (Figure 4A), the difference between using TBP alone or in combination with GUSB was minimal. The inclusion of GUSB only leads to a reduction of 0.009 in accumulated SD (Figure 3C), and the variation in fold change of $\nu W F$ between the two normalizations was insignificant (Figure 5). Similarly, the combination of TBP and YWHAZ, calculated from Normfinder, would give the same results as TBP alone. The geometric mean of this combination even had a slightly lower variance compared with that of TBP and GUSB. We suggest that TBP can be used alone or in combination with YWHAZ or GUSB for ASCs in this experimental setup.

For BMSCs, five RGs were included in the final analysis. The elimination explained earlier lead to the exclusion of EF1- $\alpha$, which is considered to be a very stable $\mathrm{RG}$, and the inclusion of GAPDH, which has been shown to be rather unstable through different treatments $[15,27,28]$. GeNorm identified the best combination of two genes to be PPIA and GAPDH (Figure 4B). However, the use of these two RGs leads to a higher accumulated $\mathrm{SD}$ (Figure 3D), and their geometric mean produced a larger fold increase in $v W F$ expression compared to the other combinations (Figure 6A).

The fact that normalizing to the geometric mean of the two genes chosen by geNorm produced a larger fold increase in $v W F$ compared to the other combinations is an example of geNorm calculating pair-wise correlation rather than stability when selecting the best suited RGs. The number of RGs to be used as suggested by Normfinder was the combination of four genes. The use of two RGs would increase the accumulated SD by 0.026 (Figure 3D), but due to practical reasons we further analyzed combinations of two genes to find the normalization that would produce the most similar result for $v W F$ expression (Figure 6B). Since TBP and $Y W H A Z$ produced results closest to the combination of the four RGs calculated by Normfinder and displayed the lowest SEM, we obtain a combination of RGs similar to that for ASCs, which could be useful in experimental setups. Except for the use of TBP as single RG, none of the $v W F$ expression results using the various combinations were significantly different from those using the four-RG Normfinder combination. However, the use of the other combinations could still produce Type 1 or Type 2 errors due to skewed expression levels or high degree of variance. The $\mathrm{C} 4 \mathrm{com}-$ bination from Figure $6 \mathrm{~B}, T B P$ and $Y W H A Z$, was the only combination significantly correlated to the four-RG
Normfinder combination. This result is of course dependent on our choice of the four-RG Normfinder combination as the most stable. In contrast to BMSCs, the different RG combinations for ASCs produced more similar $v W F$ expression results. This could be due to the seemingly larger impact of the VEGF treatment on BMSCs, which could likewise have larger influence on the RG expression, compared to standard culture. We have recently investigated the effect of VEGF treatment with serum-deprivation on ASCs, and found that the treatment did not produce endothelial differentiation to the same extent as shown earlier on BMSCs stimulated similarly $[19,22]$.

The importance of using a final GOI-specific test as supplement to results from the software before choosing RGs is especially underscored by the BMSC results. Simply following the results from geNorm would have resulted in an overestimation of the VEGF effect, which could severely bias an entire study. The software is very useful in the elimination process towards the GOIspecific test, which is evident by our results with RGs eliminated in the earlier steps. The RG candidate EF1- $\alpha$ was eliminated early on in the selection process with an expression level far from that of $v W F$. For ASCs, using $E F 1-\alpha$ as an RG would be misleading while in BMSCs there is a large variance. Normalizing to RPL13 also results in a large variance for both cell types as expected, since it was eliminated early on for high intergroup variation. The fact that EF1- $\alpha$ and RPL13 would be unsuitable to use as RGs supports our RG selection procedure.

\section{Conclusions}

For reliable and reproducible qPCR analyses, selection of the correct RGs for a given experimental setup is of prime importance. We have presented a step-by-step procedure for selecting RGs, with emphasis on a followup test with a gene of interest as the final step in the selection process. Genes were eliminated based on high intergroup variations, after which Normfinder and geNorm were applied for further selection, with a final comparison of $v W F$ expression levels for optimal RG selection. We found that the combination of TBP and YWHAZ as RGs is stable for normalization of VEGF-stimulated ASCs and BMSCs.

\section{Methods}

\section{Experimental design}

ASCs were isolated from lipoaspirate obtained from eight healthy donors of which one was male and seven were female (age between 28-57 years; mean age 43.4). BMSCs were obtained from bone marrow aspirate from eight healthy donors, two males and six females (age 20-46 years; mean age 27.8). The use of ASCs and BMSCs from healthy volunteers was approved by the 
National Ethical Committee protocol no. H-3-2009-119. All donors agreed to and signed the informed consent. After isolation and cultivation, ASCs and BMSCs were both stimulated with VEGF and compared with untreated control.

\section{Bone marrow preparation and BMSC isolation}

$50 \mathrm{ml}$ bone marrow aspirate was obtained from the iliac crest by needle aspiration under local anesthesia. The sample was diluted 1:2 with phosphate-buffered saline pH 7.4 (PBS, $-\mathrm{Ca}^{2+}-\mathrm{Mg}^{2+}$, Gibco, Invitrogen, Denmark, cat.no. 10010-015). Mononuclear cells (MNCs) were harvested by gradient centrifugation on Lymphoprep (1077 g/ $\mathrm{cm}^{3}$, Medinor, Denmark, cat.no. 1114547), washed with PBS and counted using NucleoCounter ${ }^{\circ}$ NC-100 ${ }^{\text {ma }}$ (Chemometec, Denmark) according to manufacturer's instructions. Primary cell cultures of MNCs were established by seeding $2 \times 10^{7}$ cells/T75-flask (Nunc, Thermo Scientific, Denmark, cat.no. 156494) in complete medium containing Dulbecco's Modified Eagle Medium, low glucose $(1 \mathrm{~g} / \mathrm{l})$ (DMEM) supplemented with $25 \mathrm{mM}$ HEPES and L-Glutamin, (PAA Laboratories, Austria, cat. no. E15-808), 10\% Fetal Bovine Serum Farma grade (FBS, PAA Laboratories, cat.no. A11-512) and 1\% Penicillin/ Streptomycin (Gibco, cat.no. 15140-122). The cells were incubated in standard conditions at $37^{\circ} \mathrm{C}$ in humid air with $5 \% \mathrm{CO}_{2}$. The medium was changed 5 days after initial seeding, and subsequently every $3-4$ days.

\section{Lipoaspirate preparation and ASC isolation}

Approximately $100 \mathrm{ml}$ lipoaspirate was obtained from liposuctions of subcutaneous abdominal fat performed under local anesthesia. The lipoaspirate was washed twice with PBS to remove residual blood. The adipose tissue was digested by incubation with collagenase (Collagenase NB4 (0.6 PZ U/ml, Serva GmbH, Germany) dissolved in $\mathrm{HBSS}\left(+\mathrm{CaCl}_{2}+\mathrm{MgCl}_{2}\right.$, GIBCO, cat.no. 14065-049) diluted to a concentration of $2 \mathrm{mM} \mathrm{Ca}^{2+}$ ) at $37^{\circ} \mathrm{C}$ for $45 \mathrm{~min}$. under constant rotation. The collagenase was neutralized with complete medium and the suspension was filtered through a $100 \mu \mathrm{l}$ mesh (Cell Strainer, BD Falcon, cat.no. 352360); centrifuged at $1200 \mathrm{~g}$ for $10 \mathrm{~min}$. at room temperature, re-suspended and counted. MNCs were seeded at a density of $4.5 \times 10^{6}$ cells/T75-flask in complete medium and incubated at standard conditions. After two days in culture, cells were washed with PBS to remove non-adhering leukocytes, and complete medium added anew with subsequent change of media every three-four days.

\section{Cell culture}

When the culture reached a confluence level of approximately $90 \%$, cells were washed with PBS, detached with $3 \mathrm{ml}$ TrypLE $^{\oplus}$ (TrypLE ${ }^{\oplus}$ Select, Gibco, cat.no. 12563-029) for $10 \mathrm{~min}$. at $37^{\circ} \mathrm{C}$ and neutralized with $7 \mathrm{ml}$ complete medium. The suspension was centrifuged at $300 \mathrm{~g}$ for $5 \mathrm{~min}$. at room temperature, counted, and seeded at $3.5 \times 10^{5}$ cells/T75-flask for the experimental setup. The cells exhibited stem cell characteristics, by adhering to plastic, expressing stem cell markers and being able to differentiate [22,29-31].

\section{Stimulation with VEGF}

BMSCs and ASCs were cultured in complete medium until their confluence was estimated to be $80 \%$. They were then either kept in complete medium (control), or changed to serum-deprived medium (DMEM $+2 \% \mathrm{FBS}+$ $1 \% \mathrm{P} / \mathrm{S}$ ) added $50 \mathrm{ng} / \mathrm{ml}$ recombinant human VEGF-A $\mathrm{A}_{165}$ (rhVEGFA $_{165}$, R\&D Systems, USA, cat.no. 293-VE-CF). All media was renewed every two-three days and cells were cultured for one week after which they were harvested for further processing.

\section{Nucleic acid extraction}

Total RNA was extracted using Qiagen RNeasy ${ }^{\bullet}$ Mini Kit (Qiagen Hamburg GmbH, Hamburg, Germany, cat.no. 74106) according to the manufactures protocol. $1 \mathrm{ml}$ syringe (Omnific-F $1 \mathrm{ml}$, B.Braun Melsunger AG, Germany, cat.no. 300013) was used to homogenize the lysed cells before applying the Qiagen protocol. RNA purity was measured using NanoDrop 1000 Spectrophotometer (Thermo Scientific, MA, USA), and the eluate was stored at $-80^{\circ} \mathrm{C}$. RNA purity and integrity were confirmed using RNA Nano Chips (Agilent, Santa Clara, CA, cat.no. 5067-1521) and the Agilent 2100 Bioanalyzer by following instructions of the Agilent RNA 6000 Nano Kit.

\section{Reverse transcription}

The cDNA synthesis reaction was prepared using AffinityScript (Stratagene, Denmark, cat.no. 600559) in an eighttube strip $\left(0.1 \mathrm{~mL}\right.$, MicroAmp ${ }^{\text {Tw }}$, Appied Biosystems ${ }^{\circ}$, Invitrogen, cat.no. 4358293) on ice. The total reaction volume was $20 \mu \mathrm{l}$ with $0.5 \mu \mathrm{g}$ RNA, $10 \mu \mathrm{l}$ cDNA synthesis master mix, $3 \mu$ l Oligo (dT) primer, $1 \mu$ l AffinityScript RT RNase block enzyme mixture, and RNAse-DNAse free water to $20 \mu \mathrm{l}$ total volume. Tubes were closed with caps (Applied Biosystems, cat.no. N801-0535) and the reactions were performed with an initial stage of $25^{\circ} \mathrm{C}$ for $5 \mathrm{~min}$., $42^{\circ} \mathrm{C}$ for $45 \mathrm{~min}$. and $95^{\circ} \mathrm{C}$ for $5 \mathrm{~min}$. (Veriti 96 well fast thermal cycler, Applied Biosystems model no. 9901). Following synthesis, the cDNA was stored in aliquots at $-20^{\circ} \mathrm{C}$.

\section{Quantiative real-time PCR}

qPCR was performed in triplicate per donor for each group within the same qPCR-run. A calibration curve was run simultaneously on the RG candidate tested on the donors. Only data obtained from runs fulfilling the 
same criteria for efficiency and correlation coefficient as the primer verification was included for analysis. The $\mathrm{Cq}$ threshold was set to the value of 0.1 for all qPCR runs. Brilliant II SYBR ${ }^{\circ}$ green QPCR Low ROX master mix (Agilent, cat.no. 600806) was used with a total reaction volume of $25 \mu \mathrm{l}$ in 96-well optical reaction plates (Agilent, cat.no. 401333) with $5 \mu \mathrm{l}$ of diluted cDNA. The plate was sealed with optical plastic caps (Agilent, cat.no. 401425). qPCR was performed using Mx3000 (Stratagene) and the results were collected using Mx3000 version 4.0 software for Windows (Stratagene). The reaction was initiated by heating to $95^{\circ} \mathrm{C}$ for $10 \mathrm{~min}$., followed by 40 cycles elongation at $60^{\circ} \mathrm{C}$ for $1 \mathrm{~min}$. and denaturation at $95^{\circ} \mathrm{C}$ for $30 \mathrm{sec}$.

To verify the chosen RGs, a normalization experiment was set up. $v W F$ was used as target gene, and normalized to different combinations of RG candidates. The level and the standard deviations of the fold changes between VEGF treated cells and controls were compared for normalization to different RG combinations. The fold changes in $v W F$ expression between VEGF treatment and controls were calculated with the $2^{-\Delta \Delta C q_{-}}$ method.

\section{Gel electrophoresis}

A 3\% 3-1 NuSieve agarose gel (Lonza, Switzerland, cat. no. 50090) was made according to the laboratory protocol with 1x TAE buffer diluted from 50x TAE buffer (Qiagen, cat.no. 129237). For visualization of qPCR products, 10\% non-toxic GelStar Nucleic Acid Gel Stain (Lonza, cat.no. 50535) was added to the melted agarose before pouring the solution into a plastic well with combs. After gel solidification the combs were removed and the solid gel transferred to an electrophoresis tank (BioRad, CA, USA) and covered with $1 \times$ TAE buffer. For every $8 \mu \mathrm{l}$ PCR product, $2 \mu \mathrm{l}$ Gelpilot $5 \mathrm{x}$ loading dye (Qiagen, cat.no. 1037650) was added and the $10 \mu \mathrm{l}$ sample is loaded by directly injecting into the wells. A negative control was included to show no contamination of the product. Gelpilot $1 \mathrm{~kb}$ ladder (Qiagen, cat.no. SM0318) were used. The gel was run between 70 and 100 volt in 45 min.- 60 min. and visualized under ultraviolet light.

\section{Data analysis}

Step 1. Cq values were plotted in Microsoft Excel and assessed visually for outliers in the lower end.

For further analysis, we used the GenEx software (MultiD Analyses AB, Sweden), and more specifically its algorithms Normfinder and geNorm. In short, Normfinder selects the most suitable RG based on the standard deviations (SDs) for intragroup and intergroup variation, while geNorm compares the RGs pair-wise and performs sequential elimination resulting in the best correlated
RGs. Average Cq-values of the technical triplicates were used for analysis.

Step 2. For each cell type, the mean Cq-values of all RG candidates from all donors were entered in GenEx for the treatment and control groups.

Step 3. The function Normfinder was performed taking group classification of treatment into account, in order to verify that the candidate RGs were stably expressed and not regulated by treatment. The RG candidates with SDs reaching or exceeding 0.2 were removed from the panel by inactivation in the Data Manager of GenEx before proceeding to the next step. Normfinder was run again, without taking groups into account to give the best estimate of the genes' stabilities and an assessment of the optimal number of RGs. Lastly, geNorm was run to determine the best correlated RGs. The $\Delta \Delta$ Cq-method was used when assessing the effect of VEGF treatment on the expression of $v W F$ normalized to various RGs, with subsequent use of paired t-test and Pearson's Correlation in IBM SPSS. Results were considered significant at $p$-values below 0.05 .

\section{Additional file}

Additional file 1: Table S1. RNA Quality. Table S2. Primer Quality. Figure S1. Dissociation Curves.

\section{Abbreviations}

ASC: Adipose-derived stromal cell; BMSC: Bone-marrow derived stromal cell; RG: Reference gene; VEGF: Vascular endothelial growth factor; MIQE: Minimum Information for Publication of Quantitative Real-Time PCR Experiments; RIN: RNA integrity number; 185 rRNA: 185 ribosomal RNA; ACTB: Beta-actin; EF1-a: Elongation factor 1-alpha; GAPDH: Gluco phosphate dehydrogenase; GUSB: Beta-glucuronidase; PPIA: Peptidylprolyl isomerase A; RPL13a: Ribosomal protein L13-alpha; TBP: TATA box binding protein; YWHAZ: Tyrosine 3/tryptophan 5-monooxygenase activation protein; VWF: von Willebrand factor; SD: Standard deviation; GOl: gene of interest.

\section{Competing interests}

The authors declare that they have no competing interests.

\section{Authors' contributions}

JT and BFL carried out the experiments, participated in the design of the study, performed the statistical analysis and drafted the manuscript. AE participated in the design of the study and was involved with revising the manuscript critically. JK initiated the study and revised the manuscript critically. MHS conceived of the study and contributed in the design and coordination of the study. All authors read and approved the final manuscript.

\section{Acknowledgements}

The present study was supported by Kirsten and Freddy Johansens Foundation.

Received: 30 October 2013 Accepted: 13 May 2014

Published: 28 May 2014

\section{References}

1. Abdel-Latif A, Bolli R, Tleyjeh IM, Montori VM, Perin EC, Hornung CA, Zuba-Surma EK, Al-Mallah M, Dawn B: Adult bone marrow-derived cells for cardiac repair: a systematic review and meta-analysis. Arch Intern Med 2007, 167:989-997.

2. Qayyum AA, Haack-Sorensen M, Mathiasen AB, Jorgensen E, Ekblond A, Kastrup J: Adipose-derived mesenchymal stromal cells for chronic 
myocardial ischemia (MyStromalCell Trial): study design. Regen Med 2012, 7:421-428.

3. Zhu Y, Liu T, Song K, Fan X, Ma X, Cui Z: Adipose-derived stem cell: a better stem cell than BMSC. Cell Biochem Funct 2008, 26:664-675.

4. Puissant B, Barreau C, Bourin P, Clavel C, Corre J, Bousquet C, Taureau C, Cousin B, Abbal M, Laharrague P, Penicaud L, Casteilla L, Blancher A: Immunomodulatory effect of human adipose tissue-derived adult stem cells: comparison with bone marrow mesenchymal stem cells. Br J Haematol 2005, 129:118-129.

5. Gimble JM, Katz AJ, Bunnell BA: Adipose-derived stem cells for regenerative medicine. Circ Res 2007, 100:1249-1260.

6. Ghannam S, Bouffi C, Djouad F, Jorgensen C, Noel D: Immunosuppression by mesenchymal stem cells: mechanisms and clinical applications. Stem Cell Res Ther 2010, 1:2.

7. Gnecchi M, Zhang Z, Ni A, Dzau VJ: Paracrine mechanisms in adult stem cell signaling and therapy. Circ Res 2008, 103:1204-1219.

8. Uemura R, Xu M, Ahmad N, Ashraf M: Bone marrow stem cells prevent left ventricular remodeling of ischemic heart through paracrine signaling Circ Res 2006, 98:1414-1421.

9. Caplan Al: Adult mesenchymal stem cells for tissue engineering versus regenerative medicine. J Cell Physiol 2007, 213:341-347.

10. Bustin SA, Benes V, Garson JA, Hellemans J, Huggett J, Kubista M, Mueller R, Nolan T, Pfaffl MW, Shipley GL, Vandesompele J, Wittwer CT: The MIQE guidelines: minimum information for publication of quantitative real-time PCR experiments. Clin Chem 2009, 55:611-622.

11. Chervoneva I, Li Y, Schulz S, Croker S, Wilson C, Waldman SA, Hyslop T: Selection of optimal reference genes for normalization in quantitative RT-PCR. BMC Bioinformatics 2010, 11:253.

12. Stern-Straeter J, Bonaterra GA, Hormann K, Kinscherf R, Goessler UR: Identification of valid reference genes during the differentiation of human myoblasts. BMC Mol Biol 2009, 10:66.

13. Dheda K, Huggett JF, Chang JS, Kim LU, Bustin SA, Johnson MA, Rook GA, Zumla A: The implications of using an inappropriate reference gene for real-time reverse transcription PCR data normalization. Anal Biochem 2005, 344:141-143.

14. Vandesompele J, De Preter K, Pattyn F, Poppe B, Van Roy N, De Paepe A, Speleman F: Accurate normalization of real-time quantitative RT-PCR data by geometric averaging of multiple internal control genes. Genome Biol 2002, 3(7). RESEARCH0034. 1-0034.11.

15. Fink T, Lund P, Pilgaard L, Rasmussen JG, Duroux M, Zachar V: Instability of standard PCR reference genes in adipose-derived stem cells during propagation, differentiation and hypoxic exposure. BMC Mol Biol 2008 9:98.

16. Yoon CH, Koyanagi M, lekushi K, Seeger F, Urbich C, Zeiher AM, Dimmeler S: Mechanism of improved cardiac function after bone marrow mononuclear cell therapy: role of cardiovascular lineage commitment. Circulation 2010, 121:2001-2011.

17. Friis T, Haack-Sorensen M, Mathiasen AB, Ripa RS, Kristoffersen US, Jorgensen E, Hansen L, Bindslev L, Kjaer A, Hesse B, Dickmeiss E, Kastrup K: Mesenchymal stromal cell derived endothelial progenitor treatment in patients with refractory angina. Scand Cardiovasc J 2011, 45:161-168.

18. Haack-Sorensen M, Friis T, Mathiasen AB, Jorgensen E, Hansen L, Dickmeiss E, Ekblond A, Kastrup J: Direct intramyocardial mesenchymal stromal cell injections in patients with severe refractory angina - one year follow-up. Cell Transplant 2013, 22(3):521-528.

19. Haack-Sorensen M, Friis T, Bindslev L, Mortensen S, Johnsen HE, Kastrup J: Comparison of different culture conditions for human mesenchymal stromal cells for clinical stem cell therapy. Scand J Clin Lab Invest 2008, 68:192-203.

20. Olsson AK, Dimberg A, Kreuger J, Claesson-Welsh L: VEGF receptor signalling - in control of vascular function. Nat Rev Mol Cell Biol 2006, 7:359-371.

21. Andersen $C L$, Jensen $J$, Orntoft TF: Normalization of real-time quantitative reverse transcription-PCR data: a model-based variance estimation approach to identify genes suited for normalization, applied to bladder and colon cancer data sets. Cancer Res 2004, 64:5245-5250.

22. Follin B, Tratwal J, Haack-Sorensen M, Elberg JJ, Kastrup J, Ekblond A: Identical effects of VEGF and serum-deprivation on phenotype and function of adipose-derived stromal cells from healthy donors and patients with ischemic heart disease. J Trans/ Med 2013, 11:219.
23. Veazey KJ, Golding MC: Selection of stable reference genes for quantitative rt-PCR comparisons of mouse embryonic and extra-embryonic stem cells. PLoS One 2011, 6:e27592.

24. Valente V, Teixeira SA, Neder L, Okamoto OK, Oba-Shinjo SM, Marie SK, Scrideli CA, Paco-Larson ML, Carlotti CG Jr: Selection of suitable housekeeping genes for expression analysis in glioblastoma using quantitative RT-PCR. BMC Mol Biol 2009, 10:17.

25. Curtis KM, Gomez LA, Rios C, Garbayo E, Raval AP, Perez-Pinzon MA, Schiller PC: EF1alpha and RPL13a represent normalization genes suitable for RT-qPCR analysis of bone marrow derived mesenchymal stem cells. BMC Mol Biol 2010, 11:61

26. Wang Y, Han Z, Yan S, Mao A, Wang B, Ren H, Chi Y: Evaluation of suitable reference gene for real-time PCR in human umbilical cord mesenchymal stem cells with long-term in vitro expansion. In Vitro Cell Dev Biol Anim 2010, 46:595-599.

27. Everaert BR, Boulet GA, Timmermans JP, Vrints CJ: Importance of suitable reference gene selection for quantitative real-time PCR: special reference to mouse myocardial infarction studies. PLoS One 2011, 6:e23793.

28. Condori J, Nopo-Olazabal C, Medrano G, Medina-Bolivar F: Selection of reference genes for $\mathrm{qPCR}$ in hairy root cultures of peanut. BMC Res Notes 2011, 4:392.

29. Friis T, Haack-Soorensen M, Hansen SK, Hansen L, Bindslev L, Kastrup J: Comparison of mesenchymal stromal cells from young healthy donors and patients with severe chronic coronary artery disease. Scand J Clin Lab Invest 2011, 71:193-202.

30. Bourin P, Bunnell BA, Casteilla L, Dominici M, Katz AJ, March KL, Redl H, Rubin JP, Yoshimura K, Gimble JM: Stromal cells from the adipose tissue-derived stromal vascular fraction and culture expanded adipose tissue-derived stromal/stem cells: a joint statement of the International Federation for Adipose Therapeutics and Science (IFATS) and the International Society for Cellular Therapy (ISCT). Cytotherapy 2013, 15:641-648.

31. Dominici M, Le Blanc K, Mueller I, Slaper-Cortenbach I, Marini F, Krause D, Deans R, Keating A, Prockop D, Horwitz E: Minimal criteria for defining multipotent mesenchymal stromal cells. The International Society for Cellular Therapy position statement. Cytotherapy 2006, 8:315-317.

doi:10.1186/1471-2199-15-11

Cite this article as: Tratwal et al:: Identification of a common reference gene pair for qPCR in human mesenchymal stromal cells from different tissue sources treated with VEGF. BMC Molecular Biology 2014 15:11.

\section{Submit your next manuscript to BioMed Central and take full advantage of:}

- Convenient online submission

- Thorough peer review

- No space constraints or color figure charges

- Immediate publication on acceptance

- Inclusion in PubMed, CAS, Scopus and Google Scholar

- Research which is freely available for redistribution

Submit your manuscript at www.biomedcentral.com/submit
C) Biomed Central 